\title{
O Fim da Guerra Química e a Organização para a Proibição DAS ARMAS QUIMIICAS (OPAQ)
}

\author{
Cristina Baptista Rodrigues* \\ cris.baptista.rodrigues@gmail.com
}

\begin{abstract}
The Organisation for the Prohibition of Chemical Weapons (OPCW) and the End of Chemical Wars - Nothing better than the year of the centenary of the outbreak of World War I, where there was an intensive use of chemical weapons, to make known the Convention for the Prohibition of Chemical Weapons and the work of the Organization that has the mission to create a world free of such weapons of mass destruction - the Organisation for the Prohibition of Chemical Weapons (OPCW).
\end{abstract}

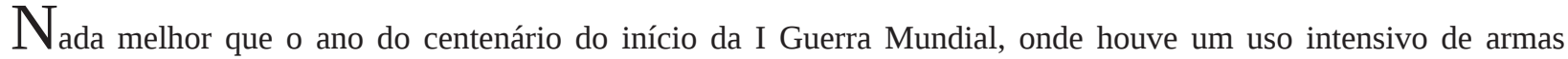
químicas, para dar a conhecer a Convenção para a Proibição das Armas Químicas e o trabalho da Organização que tem por missão criar um mundo livre deste tipo de armas de destruição maciça - a Organização para a Proibição das Armas Químicas (OPAQ).

\section{A ORGANIZAÇÃO PARA A PROIBIÇÃO DAS ARMAS QUÍMICAS}

Um ano depois de ter ganhado o Prémio Nobel da Paz de 2013 (Figura 1), a Organização para a Proibição das Armas Químicas (OPAQ, internacionalmente conhecida como OPCW - Organisation for the Prohibition of Chemical Weapons) continua a ser para uma grande maioria dos químicos, uma ilustre desconhecida.

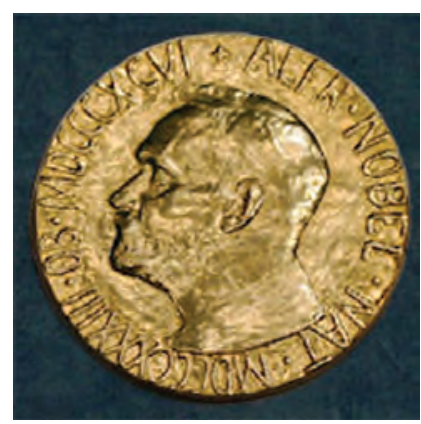

Figura 1 - Medalha do Prémio Nobel da Paz 2013

A OPAQ surgiu em 29 Abril de 1997 como a organização responsável pela implementação da Convenção para a Proibição das Armas Químicas (CPAQ) [1], assinada em 13 de Janeiro de 1993 por 130 países (Figura 2).

A CPAQ é o primeiro tratado mundial com um sistema de verificação para banir e verificar a eliminação e não proliferação de uma categoria de armas de destruição maciça. Dezassete anos após a criação da OPAQ, a Convenção para a Proibição das Armas Químicas é o tratado multinacional de desarmamento com maior implementação, abrangendo 98\% da humanidade. Apenas seis países se encontram fora da Convenção: Israel, Mianmar, Angola, Coreia do Norte, Egipto e Sudão do Sul. De acordo com dados relativos a Setembro de 2014, 82,78 \% do total declarado de 72524 to-

\footnotetext{
* Ex-Chefe do Departamento de Assistência e Protecção da OPAQ
}

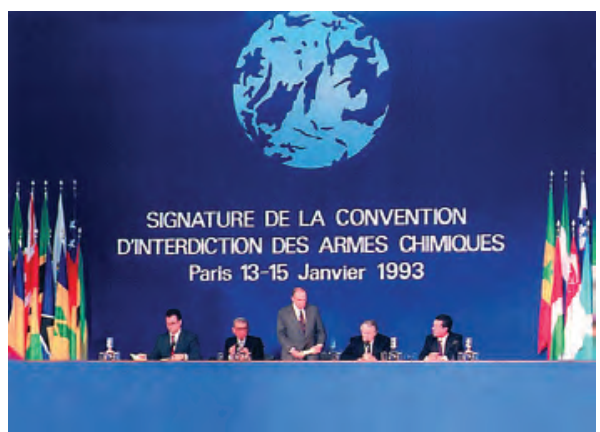

Figura 2 - Assinatura da Convenção para a Proibição das Armas Químicas

neladas de armas químicas já foi destruído. Estes números incluem o arsenal sírio que foi declarado e extraído de um país em guerra civil e destruído num período de tempo de pouco mais de dez meses.

\section{BREVE HISTÓRIA DAS ARMAS QUÍMICAS E DO SEU DESAR- MAMENTO}

O uso de produtos químicos em guerra devido às suas propriedades tóxicas data da Antiguidade. Um dos primeiros casos descritos foi o uso durante a Guerra do Peloponeso (431-404 a.C.) no ataque à cidade de Plateia, onde uma nuvem de vapores de dióxido de enxofre provocado pela queima de madeira saturada em alcatrão e enxofre cobriu a cidade sitiada [2].

O uso do "fogo grego" pelos bizantinos em batalhas navais é outro exemplo de uso de um produto químico em guerra na Antiguidade. A composição do fogo grego ainda se mantem em discussão, acreditando-se ser uma mistura de petróleo, nafta, fosfito de cálcio e nitrato de potássio.

Durante muito tempo o uso de produtos químicos em guerra não era considerado adequado militarmente devido ao desconhecimento científico e à incapacidade de sintetizar 
produtos cuja toxicidade fosse suficientemente grande para serem aplicados em guerra. Um outro factor dissuasor era o sentido moral de alguns militares que consideravam a utilização de substâncias venenosas como não éticas.

No entanto, com o desenvolvimento da Química e a criação de novos produtos químicos, no século XIX houve, por parte dos países, esforços para limitar o uso de veneno ou armas envenenadas em guerra por se considerar o uso destas armas como inumanas e de efeitos incontroláveis e indiscriminados, em linha com a Declaração de Bruxelas de 1874. Uma revisão desta Declaração foi feita na Conferência Internacional da Paz em Haia de 1899, que proibiu o emprego de projécteis que dispersassem gases asfixiantes [3].

Em Agosto de 1914, as tropas francesas usaram bombas de bromoacetato de etilo (Figura 3), uma substância com actividade lacrimogénia, para forçar os alemães a saírem das trincheiras. Esse ataque foi ineficaz em termos militares devido às pequenas quantidades, que se dispersavam muito rapidamente quando usadas ao ar livre. Estes ataques foram utilizados pelos alemães, em especial por Fritz Haber, para criar o argumento de que não eram os primeiros a quebrar a Convenção de Haia. Além do mais, os aliados tinham feito um embargo aos nitratos importados pela Alemanha e usados na fabricação de explosivos. Após várias tentativas utilizando clorossulfonato de $o$-anisidina (Figura 3), um produto pouco tóxico mas produzido em grandes quantidades na indústria das tintas, os alemães lançaram um ataque maciço no dia 22 de Abril de 1915 às cinco horas da tarde em Ypres, Bélgica, onde 168 toneladas de cloro foram libertadas a partir de 6000 recipientes ao longo de vários quilómetros da frente, causando cerca de 15000 baixas, incluindo 3000 vítimas mortais [4]. Apesar do ataque ter sido devastador, não teve o impacto esperado pelos militares alemães.

Em Setembro de 1915, os ingleses dispersaram 150 toneladas de cloro que causaram mais baixas nos próprios solda- dos ingleses que no inimigo devido à alteração da direcção do vento [5].

Foram, entretanto, desenvolvidos respiradores primitivos compostos de panos embebidos em água e urina que eram usados como máscaras e limitavam o efeito do cloro. No final de 1915, a Alemanha usou pela primeira vez fosgénio (Figura 3) e os ingleses um ano mais tarde. Os franceses, desde o início da guerra, dedicavam-se ao estudo do uso do cianeto de hidrogénio sem grandes resultados uma vez que é um agente pouco persistente (muito volátil) e menos denso que o ar, o que fazia com que a sua utilização em campo aberto fosse muito pouco eficaz.

Um outro momento importante na história da guerra química foi o uso em 1917, pelos alemães, de iperite (Figura 3), conhecido por gás mostarda ou mostarda de enxofre e cujo nome IUPAC é sulfureto de bis(2-cloroetilo). A iperite é, na realidade, um líquido com um alto ponto de ebulição $\left(218{ }^{\circ} \mathrm{C}\right)$, pouco solúvel em água, que em contacto com a pele causa lesões com um período de latência de várias horas. Estas lesões aparecem sob a forma de ampolas nas zonas do corpo onde se acumula o suor, uma vez que é um forte agente alquilante que inclui no seu mecanismo de acção a presença de água [2]. A iperite alterou significativamente o conceito de equipamento de protecção individual uma vez que o uso da protecção respiratória se mostrava insuficiente. A iperite e os outros agentes vesicantes que se lhe seguiram requeriam o desenvolvimento de uniformes e luvas para proteger a pele dos soldados o que, ao mesmo tempo, diminuía a mobilidade e o conforto dos combatentes.

Outras substâncias foram utilizadas durante a I Guerra Mundial (Figura 3), num total de mais de 124000 toneladas de 21 produtos químicos diferentes, tendo morrido cerca de 90000 pessoas [6] e, aproximadamente, 1,3 milhões de pessoas sofreram os seus efeitos [1]. Estes dados não reflectem um número desconhecido de casos de "pneumonia química”, um tipo de cancro causado pelo gás mostarda.
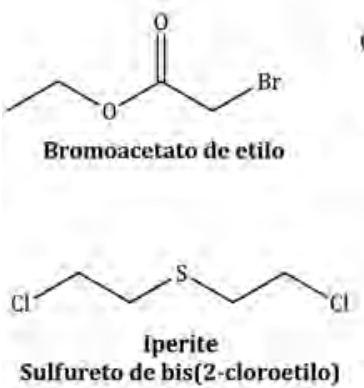

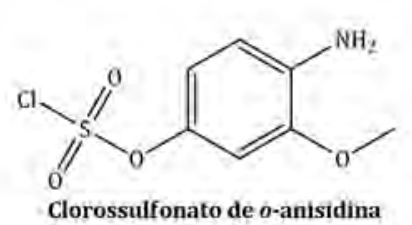

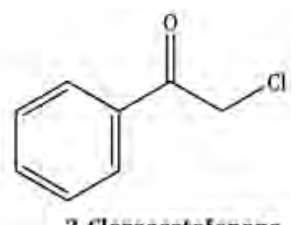

2-Cloroacetofenona

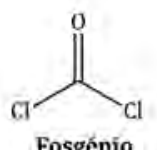

Fosgénio

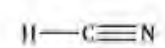

Cianeto de hidrogénio
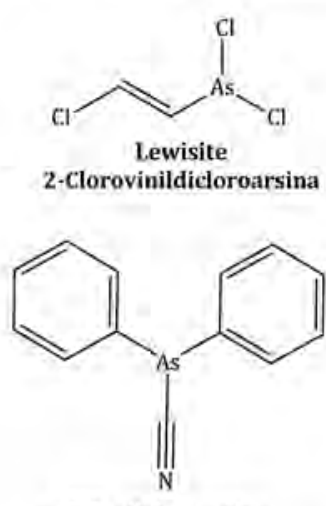

Difenilcianoarsina

Figura 3 - Exemplos de compostos químicos usados como armas químicas durante a I Guerra Mundial 
<smiles>CCOP(=O)(C#N)N(C)C</smiles>

Tabun (GA)<smiles>CC(C)OP(C)(=O)F</smiles><smiles>CC(OP(C)(=O)F)C(C)(C)C</smiles>

Soman (GD)<smiles>CCOP(C)(=O)SCCN(C(C)C)C(C)C</smiles>

$\mathrm{vX}$<smiles>CCN(CC)CCSP(C)(=O)OCC(C)C</smiles>

VR

Figura 4 - Estruturas dos gases de nervos

Apesar de o número de vítimas de armas químicas não ser muito grande em relação ao número total de baixas durante a I Guerra Mundial (dez milhões de militares e sete milhões de civis), a opinião pública estava aterrorizada e opunha-se fortemente ao seu uso. O Protocolo de Genebra, assinado em 1925 por todas as grandes potências da época, excepto os Estados Unidos e o Japão, proibiu “o uso em guerra de gases asfixiantes, venenosos ou outros e todos os análogos líquidos, materiais ou dispositivos que foram justamente condenados pela opinião pública do mundo civilizado" [7]. No entanto, não proíbe a posse de agentes ou o seu uso em caso de retaliação. A existência deste protocolo não impediu, no entanto, o uso deste tipo de armamento quer por estados que ratificaram o protocolo de Genebra, como a Itália que usou gás mostarda na Abissínia em 1935-1936, quer pelo Japão contra a China (1937-1938). Os japoneses começaram por usar 2-cloroacetofenona (Figura 3), um agente de controlo de motins, mas também difenilcianoarsina (Figura 3) e iperite. As tropas chinesas que não possuíam nenhum tipo de protecção retiravam-se quando confrontadas com o uso dos agentes químicos [8].

Durante a década de 1930, e como resultado da investigação sobre novos pesticidas, os químicos alemães da IG Farben em Leverkusen descobriram os gases de nervos. Gerhard Schrader sintetizou pela primeira vez tabun (GA; $N, N$-dimetilfosforamidocianidato de etilo (Figura 4) em 1936. A Alemanha produziu cerca de 12000 toneladas de tabun desde 1942 até 1945 . O sarin (GB; metilfosfonofluoridrato de $O$-isopropilo (Figura 4) foi descoberto em 1938 mas a sua produção envolvia o uso de produtos químicos altamente corrosivos que criaram diversos problemas na sua produção, que apenas atingiu 500 toneladas. O soman (GD; metilfosfonofluoridrato $O$-pinacolilo (Figura 4) foi descoberto em 1944 pelo grupo de Richard Kuhn no Instituto Kaiser (prémio Nobel da Química em 1938). Estes compostos foram depois desenvolvidos como armas pelo regime Nazi que os armazenou mas nunca os usou durante a II Guerra Mundial.

Não só a Alemanha tinha arsenal químico; todas as outras grandes potências da época anteciparam o uso deste tipo de armamento durante a II Guerra Mundial apesar de isso não ter acontecido, tendo inclusive sido feito cartazes alusivos às suas propriedades (Figura 5). As razões são incertas e ainda em discussão por alguns historiadores, parecendo que o medo de retaliação, o desconhecimento dos arsenais inimigos, o estigma das armas químicas junto da opinião pública e o nível de protecção disponível tiveram um efeito dissuasor.

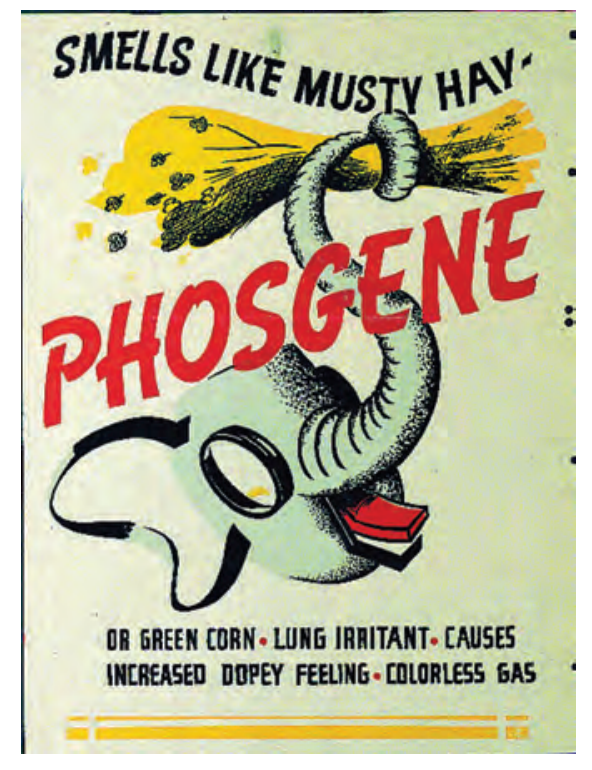

Figura 5 - Poster da II Guerra Mundial [9]

Depois da II Guerra Mundial, o arsenal alemão foi dividido pelos aliados bem como os seus técnicos. A União Soviética transferiu grandes quantidades de munições para a Rússia e as fábricas de produção do Terceiro Reich ficaram dentro da esfera de controlo soviético. Uma grande parte do arsenal foi lançado ao mar Báltico e no estreito de Skagerrak [10] onde ainda hoje causam problemas ambientais.

A seguir à II Guerra Mundial os Estados Unidos continuaram a investigação dos mecanismos de acção dos gases de nervos para desenvolvimento de protecção mais eficaz. Ranajit Ghosh e J. F. Newman sintetizaram amiton (VG; S-[2-(dietilamino)etil]fosforotiolato de O,O-dietilo) (Fi- 
gura 6) em 1952 pela primeira vez. Após diversos testes concluíram que se tratava de uma substância muito tóxica para o homem, não tendo por isso muitas utilizações civis. Os químicos militares alteraram ligeiramente a molécula para a tornar mais persistente, criando o VX (S-[2-(diisopropilamino)etil]metilfosfonotioato de $\mathrm{O}$-etilo) (Figura 4). Mais tarde, os cientistas russos desenvolveram o VR ( $N, N$-dietil-2-(metil-(2-metilpropoxi)fosforil)sulfaniletanamina) (Figura 4), mais conhecido por VX Russo [6].

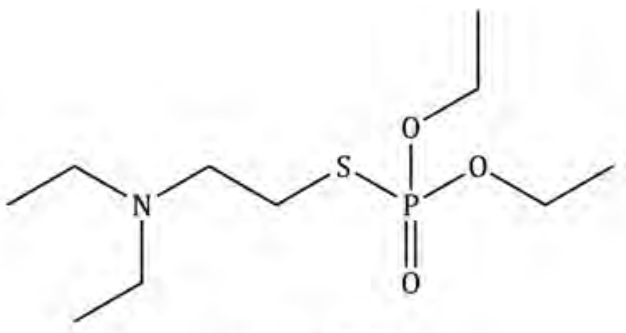

Amiton (VG)

Figura 6 - Estrutura do amiton

Os gases de nervos são todos líquidos à temperatura ambiente e possuem diferente volatilidade, sendo os agentes G (tabun, sarin e soman) bastante mais voláteis que os agentes $\mathrm{V}$, que são mais persistentes (Tabela 1).
Os gases de nervos, assim como outros pesticidas organofosforados, são inibidores da enzima acetilcolinesterase que degrada a acetilcolina. $\mathrm{O}$ seu efeito baseia-se na actuação dos fosfatos orgânicos por fosforilação de enzimas que contenham um resíduo de serina nos seus sítios activos, entre elas a acetilcolinesterase, inactivando-as. A acetilcolinesterase é responsável pela degradação de acetilcolina, um neurotransmissor. A acumulação da acetilcolina nas sinapses, em resultado da inactivação da acetilcolinesterase, provoca hiperestimulação colinérgica, com efeitos tóxicos para o sistema nervoso autónomo, para o sistema nervoso central e para as junções neuromusculares. Os efeitos nocivos caracterizam-se por sudação e vómitos seguidos de perda do controlo muscular, sensação de opressão no tórax, convulsões e, finalmente, morte por asfixia. Em doses suficientemente altas, a morte é instantânea. Na realidade, com apenas uma gota na pele, o agente VX, por exemplo, pode matar um ser humano em poucos minutos.

Durante a Guerra Fria, outros compostos foram desenvolvidos por diversas potências, sendo os mais conhecidos os agentes incapacitantes como o BZ (benzilato de 3-quinuclidinilo) criado pelos norte-americanos e os agentes neurotóxicos onde não existe ligação carbono-fósforo, os novichok, desenvolvidos pelos russos desde os anos 70 e 80 e publicados em 1992 já depois das negociações da CPAQ (Figura 7).

Tabela 1 - Propriedades de alguns gases de nervos

\begin{tabular}{|c|c|c|c|c|}
\hline & $\begin{array}{c}\text { Tabun } \\
(\mathrm{GA})\end{array}$ & Sarin (GB) & Soman (GD) & VX \\
\hline Densidade $\left(\mathrm{g} / \mathrm{cm}^{3}\right)\left(25^{\circ} \mathrm{C}\right)$ & 1,073 & 1,102 & 1,022 & $1,012\left(20^{\circ} \mathrm{C}\right)$ \\
\hline $\mathrm{P}_{\mathrm{e}}\left({ }^{\circ} \mathrm{C}\right)$ & 247 & 147 & 167 (decomp.) & 298 \\
\hline $\mathrm{P}_{\mathrm{f}}\left({ }^{\circ} \mathrm{C}\right)$ & -50 & -56 & -42 & -39 \\
\hline Pressão de vapor $\left(\mathrm{mm} \mathrm{Hg}, 25^{\circ} \mathrm{C}\right)$ & 0,07 & 2,9 & 0,4 & 0,0007 \\
\hline Volatilidade $\left(\mathrm{mg} / \mathrm{m}^{3}, 25^{\circ} \mathrm{C}\right)$ & 610 & $29.800\left(30{ }^{\circ} \mathrm{C}\right)$ & 3.900 & 10,5 \\
\hline Solubilidade em água $\%(\mathrm{~m} / \mathrm{m})\left(25^{\circ} \mathrm{C}\right)$ & 10 & $\infty$ & 2 & $3\left(\infty<9,5{ }^{\circ} \mathrm{C}\right)$ \\
\hline IDLH $\left(\mathrm{mg} / \mathrm{m}^{3}\right)[11]$ & 0,1 & 0,1 & 0,1 & 0,003 \\
\hline
\end{tabular}<smiles>O=C(OC1CN2CCC1CC2)C(O)(c1ccccc1)c1ccccc1</smiles><smiles>[X]C([X])=NOP([R])([R])=O</smiles>

Novichok

$\mathrm{R}=$ alquilo, alcoxi, alquilamino $\mathrm{X}=\mathrm{F}, \mathrm{Cl}, \mathrm{Br}, \mathrm{CN}$

Figura 7 - Estruturas do benzilato de 3-quinuclidinilo (BZ) e agentes novichok 
Também as munições sofreram um grande desenvolvimento durante a guerra fria com o aparecimento das armas binárias. Neste tipo de sistema, a reacção de produção do agente químico é feita dentro da munição, o que aumenta a segurança da manipulação e do transporte para o teatro de guerra.

E quanto ao uso de armas químicas depois de 1945? Os casos mais conhecidos são o uso pelo Iraque durante a Guerra Irão-Iraque entre 1982 e 1988. O governo de Sadam Hussein utilizou iperite e tabun contra as tropas iranianas em diversas ocasiões, causando um total de mais de 30000 baixas, e sarin contra a população curda de Halabja em 16 de Março de 1988, causando mais de 2000 vítimas entre as quais mulheres e crianças [12].

Contudo foi a seita japonesa Aum Shimriko que marcou o início de uma era quando produziu e utilizou sarin em Matsumoto em 1994 e no metro de Tóquio em 1995. Pela primeira vez, uma organização terrorista utilizou armas de destruição maciça contra a população civil causando o pânico. Estes dois ataques não causaram um elevado número de baixas (doze mortos em Tóquio e sete em Matsumoto) mas a mácula da utilização de armas químicas fez destes ataques um marco da História.

Em 21 Agosto de 2013, aquando da primeira investigação conjunta das Nações Unidas e da OPAQ à Síria, nos subúrbios de Damasco, não muito longe do hotel onde se hospedavam os inspectores internacionais, ocorreu um ataque com sarin com mais de 3600 vítimas civis [13]. Este ataque impressionou a opinião pública e desencadeou um movimento mundial de indignação que culminou com a adesão da Síria à CPAQ e a destruição do arsenal químico sírio.

A extracção do arsenal num estado em guerra civil e a sua destruição representou o maior desafio que a OPAQ enfrentou e superou durante a sua existência. Este não foi, no entanto, o último caso de uso de armas químicas. Uma investigação levada a cabo pela OPAQ no último mês de Maio concluiu que tinha sido utilizado também cloro em aldeias no Norte da Síria no início de 2014 [14].

\section{DEFINIÇÃO DE ARMA QUÍMICA}

Mas afinal o que é uma arma química? E que produtos químicos são usados em munições químicas (tal como mostra a Figura 8)?

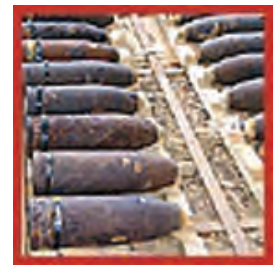

Figura 8 - Munições químicas
De acordo com a CPAQ, a definição de armas químicas contempla não só os agentes químicos de guerra mas também outros compostos que pela sua acção química possa causar danos aos seres vivos. Esta definição encontra-se no Artigo II da Convenção [1]:

“1-Por "armas químicas” entende-se, conjunta ou separadamente, o seguinte:

a) Os produtos químicos tóxicos e seus precursores, excepto quando se destinem a fins não proibidos pela presente Convenção, desde que os tipos e as quantidades desses produtos sejam compatíveis com esses fins;

b) As munições e dispositivos especificamente concebidos para causar a morte ou provocar lesões através das propriedades tóxicas dos produtos químicos especificados na alínea a), quando libertados como resultado da utilização dessas munições ou dispositivos;

c) Qualquer equipamento especificamente concebido para ser utilizado em relação directa com a utilização das munições e dispositivos especificados na alínea b).

2 - Por "produto químico tóxico" entende-se todo o produto químico que, pela sua acção química sobre os processos vitais, possa causar a morte, a incapacidade temporária ou lesões permanentes em seres humanos ou animais. Ficam abrangidos todos os produtos químicos deste tipo, independentemente da sua origem ou método de produção, e quer sejam produzidos em instalações, como munições ou de outra forma."

A CPAQ divide os produtos químicos que controla em três listas diferentes. Na Lista 1 constam os agentes químicos de guerra; os compostos com uma estrutura química semelhante que se preveja terem propriedades toxicológicas semelhantes; os precursores dos agentes químicos da última etapa da síntese dos compostos previamente descritos, quer esta síntese aconteça nas instalações fabris quer nas munições, e que não tenham mais nenhuma outra aplicação, como os descritos na Tabela 2.

Na Lista 2, a Lista 2A inclui os produtos químicos tóxicos não enumerados na Lista 1 (Tabela 3); a Lista 2B abrange os precursores relacionados com os produtos da Lista 1 ou com os produtos anteriores com pouca utilização industrial, como por exemplo o tricloreto de arsénio ou tiodiglicol, entre outros.

A Lista 3 é composta pelos produtos químicos tóxicos que já foram produzidos, armazenados ou utilizados como armas químicas ou são precursores de agentes químicos de guerra mas que são produtos comuns na indústria química (Tabela 4).

\section{SPQ - Sociedade Portuguesa de Química | www.spq.pt}


Tabela 2 - Exemplos de compostos da Lista 1 da CPAQ

\begin{tabular}{|c|c|c|}
\hline Nome & Nome IUPAC & CAS \\
\hline Sarin & Metilfosfonofluoridrato de $O$-isopropilo & $107-44-8$ \\
\hline Soman & Metilfosfonofluoridrato de $O$-pinacolilo & 96-64-0 \\
\hline Tabun & $\mathrm{N}, \mathrm{N}$-dimetilfosforamidocianidato de $\mathrm{O}$-etilo & 77-81-6 \\
\hline VX & S-[2-(Diisopropilamino)etil]metilfosfonotiolato & 50782-69-9 \\
\hline Iperite (mostarda de enxofre) & Sulfureto de bis(2-cloroetilo) & $505-60-2$ \\
\hline Lewisite & 2-Clorovinildicloroarsina & $541-25-3$ \\
\hline Mostarda de azoto & Bis(2-cloroetil)etilamina & $538-07-8$ \\
\hline Saxitoxina & $\begin{array}{c}\text { 3aS-(3a- } \alpha, 4-\alpha, 10 \mathrm{aR} *))-2,6-d i a m i n o-4-(((a m i n o-c a r b o n i l) \\
\text { oxi)metil)-3a,4,8,9-tetra-hidro-1H,10H-pirrolo(1,2-c) } \\
\text { purina-10,10-diol }\end{array}$ & 35523-89-8 \\
\hline Ricina & - & $9009-86-3$ \\
\hline DF & Difluoreto de metilfosfonilo & 676-99-3 \\
\hline QL & $O$-2-Diisopropilaminoetilmetilfosfonito de $O$-etilo & 57856-11-8 \\
\hline Clorosarin & Metilfosfonocloridrato de $O$-isopropilo & 1445-76-7 \\
\hline Clorosoman & Metilfosfonocloridrato de $O$-pinacolilo & 7040-57-5 \\
\hline
\end{tabular}

Tabela 3 - Produtos químicos da Lista 2A da CPAQ

\begin{tabular}{|c|c|c|}
\hline Nome & Nome IUPAC & CAS \\
\hline Amiton & $S$-[2-(Dietilamino)etil]fosforotiolato de O,O-dietilo & $78-53-5$ \\
\hline PFIB & 1,1,3,3,3-Pentafluoro-2-(trifluorometil)prop-1-eno & $382-21-8$ \\
\hline BZ & Benzilato de 3-quinuclidinilo & $6581-06-2$ \\
\hline
\end{tabular}

Tabela 4 - Produtos químicos da Lista 3 da CPAQ

\begin{tabular}{|c|c|}
\hline Nome & CAS \\
\hline Fosgénio (Dicloreto de carbonilo) & $75-44-5$ \\
\hline Cloreto de cianogénio & $506-77-4$ \\
\hline Cianeto de hidrogénio & $74-90-8$ \\
\hline Cloropicrina (Tricloronitrometano) & $76-06-2$ \\
\hline Oxicloreto de fósforo* & $10025-87-3$ \\
\hline Tricloreto de fósforo* & $7719-12-2$ \\
\hline Pentacloreto de fósforo* & $10026-13-8$ \\
\hline Fosfito de trimetilo* & $121-45-9$ \\
\hline Fosfito de dietilo* & $122-52-1$ \\
\hline Monocloreto de enxofre* & $10025-67-9$ \\
\hline Dicloreto de enxofre* $^{*}$ & $10545-99-0$ \\
\hline Cloreto de tionilo* $^{*}$ & $7719-09-7$ \\
\hline Etildietanolamina* & $139-87-7$ \\
\hline Metildietanolamina* & $105-59-9$ \\
\hline Trietanolamina* & $102-71-6$ \\
\hline
\end{tabular}

* precursores

\section{A CONVENÇÃO PARA A PROIBIÇÃO dAS ARMAS QUÍMICAS}

Mas como funciona a Convenção? Como é feito o controlo da destruição dos arsenais de armas químicas e que outros mecanismos contém a Convenção que assegurem a não proliferação deste tipo de armamento? A CPAQ baseia-se em quatro pilares principais: dois relacionados com o controle dos arsenais e não proliferação, e dois de apoio ao desenvolvimento dos Estados Parte da Convenção.

DESTRUIÇÃO DOS ARSENAIS QUÍMICOS E VERIFICAÇÃO DA NÃO PROLIFERAÇÃO

Dois dos pilares da CPAQ estão relacionados com o controlo e destruição de armas químicas e baseiam-se no estudo e aprovação dos processos de destruição dos produtos químicos tóxicos e das instalações de produção declarados pelos países possuidores; no controle permanente aos locais de destruição dos produtos da Lista 1; e em inspecções às instalações industriais que produzem, importam, armazenem ou consomem os produtos listados nas Listas 2 e 3 ou que produzem quantidades superiores a trinta toneladas de produtos químicos orgânicos individuais que conte- 
nham flúor, fósforo ou enxofre, ou quantidades superiores a 200 toneladas de outros produtos químicos orgânicos individuais.

Os países possuidores são responsáveis pela destruição de todo o arsenal e das instalações de produção. São também responsáveis pela criação e manutenção de estruturas para a destruição das munições (Figura 9) e dos produtos químicos tóxicos. Estas estruturas são monitorizadas pelos inspectores da OPAQ. Estes mantêm também um controlo apertado sobre os locais de armazenamento dos arsenais químicos a destruir.

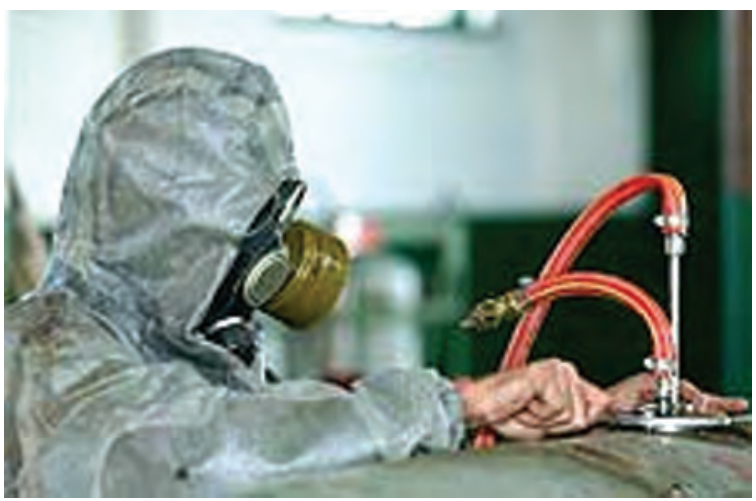

Figura 9 - Desmantelamento de uma munição

As indústrias abrangidas pela Convenção têm de declarar, sessenta dias antes do início de cada ano civil, a quantidade de produtos químicos prevista produzir e consumir durante o ano seguinte e, noventa dias após o final do ano civil, a quantidade de produtos químicos abrangidos, produzidos ou consumidos no ano transacto. Estas declarações são compiladas por uma estrutura nacional, a Autoridade Nacional para a CPAQ responsável por fazer o contacto com a OPAQ e por comunicar estes dados. A Autoridade Nacional é também responsável por compilar os totais nacionais de produtos importados/exportados pelas empresas no país e informar a OPAQ desses totais.

Assim, a OPAQ consegue não só ter controlo sobre a destruição dos produtos da Lista 1 mas também verificar a utilização de outros produtos químicos, que poderão ser usados para produzir novas armas químicas. De Abril de 1997 até Setembro de 2014, num total de 4913 instalações fabris inspeccionáveis em 86 países, a organização efectuou 5545 inspecções, tendo sido verificadas 265 instalações relacionadas com armas químicas e 2024 instalações industriais.

OS PILARES DA CPAQ DE APOIO AO DESENVOLVIMENTO DOS ESTADOS PARTE: ASSISTÊNCIA E PROTECÇÃO E COOPERAÇÃO INTERNACIONAL

Os estados, ao assinarem a CPAQ, garantem o direito a receber, da parte da organização, assistência e protecção se armas químicas forem usadas contra si. A CPAQ também apoia o desenvolvimento do uso da Química para fins pacíficos através de mecanismos de cooperação internacional.

Em termos de assistência e protecção a OPAQ gere ofertas feitas pelos diversos Estados Parte em termos de equi- pamento, apoio médico e medicamentos, conhecimentos técnicos e formação (Figuras 10-12). Esta assistência pode ser preventiva, pois prepara os Estados para responder a um ataque com armas químicas, ou activa, ao coordenar a assistência a um Estado que tenha sido atacado com este tipo de armamento.

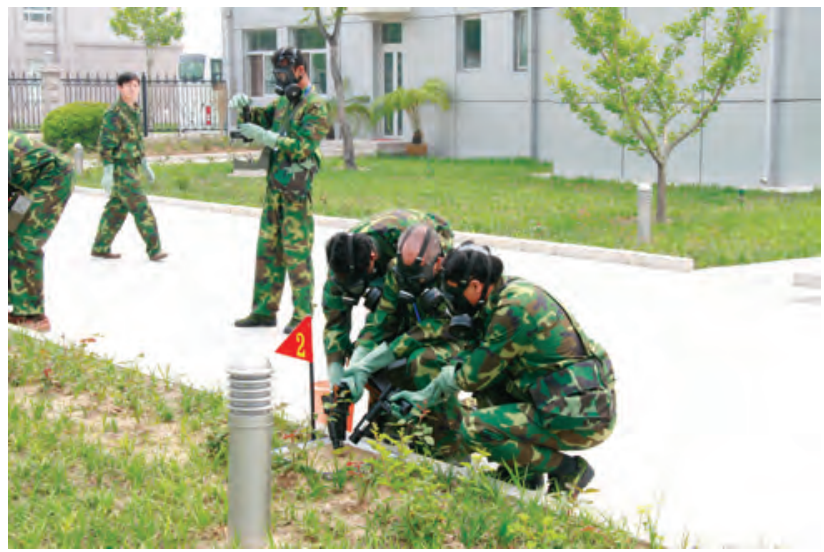

Figura 10 - Curso de assistência e protecção em 2008 na China

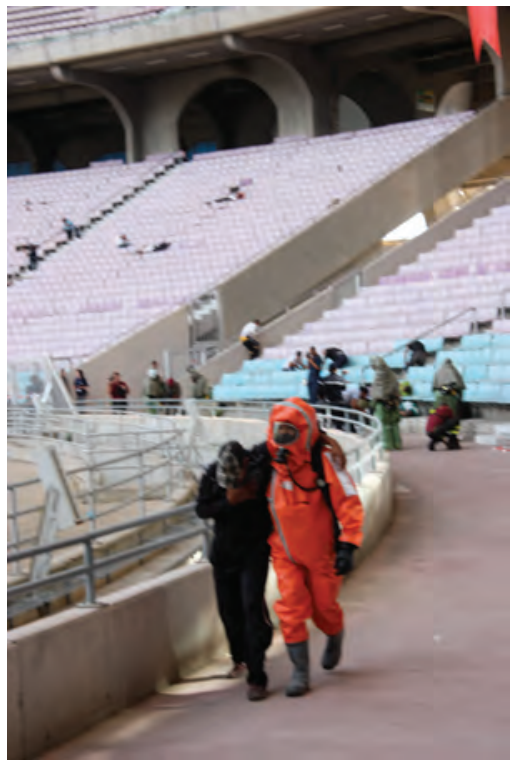

Figura 11 - Exercício de assistência e protecção na Tunísia

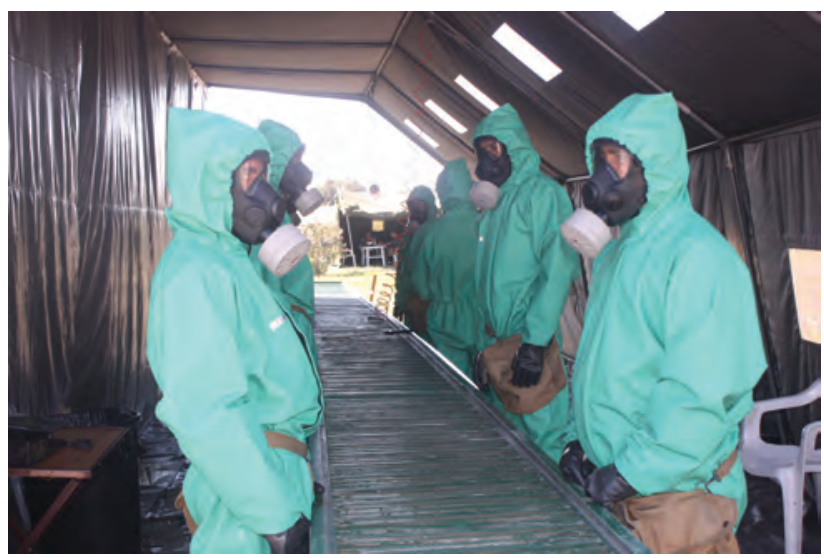

Figura 12 - Exercício de descontaminação

A formação prevista pelo mandato da OPAQ aos Estados está dirigida à criação de resposta a ataques com armas químicas. Em termos práticos, para a maioria dos países, o im- 
portante é o trabalho que a Organização faz para criar capacidade de resposta a qualquer tipo de incidente químico quer ele seja de origem bélica, criminosa ou acidental. Este apoio revela-se extremamente importante, especialmente para países com menores recursos onde o aconselhamento técnico oferecido pela organização permite desenvolver ou até criar o plano nacional de emergências químicas.

A cooperação internacional para o desenvolvimento da Química, conforme está descrito nos termos do artigo XI da CPAQ [1], apoia a comunidade científica no desenvolvimento da capacidade científica nacional em Química, Engenharia Química e disciplinas afins. A CPAQ reconhece que a educação e o conhecimento são fundamentais para o desenvolvimento de aplicações pacíficas e éticas da Química, que contribuem para o progresso socioeconómico dos Estados Membros [15]. Para isso a CPAQ organiza estágios, apoia conferências, organiza formação em diversas áreas da Química, como a química analítica, segurança química (Safety and Security), entre outras.

Estes dois pilares e o apoio às Autoridades Nacionais fazem da CPAQ não só o único tratado internacional que destrói uma categoria de armas de destruição maciça, mas também um mecanismo de apoio ao desenvolvimento dos pequenos países signatários da Convenção.

\section{E DEPOIS DA DESTRUIÇÃO DOS ARSENAIS...}

Faz sentido a OPAQ continuar a existir e em que moldes?

A discussão do futuro da organização após a destruição dos arsenais declarados ganhou relevância em 2010 aquando da tomada de posse do actual Director-geral, Embaixador Ahmet Üzümcü. No entanto, a queda de Muhamar Khadafi na Líbia e a guerra civil na Síria fizeram a OPAQ lembrar-se de que sem a Convenção ter atingido a universalidade não há garantias de um mundo livre de armas químicas.

A CPAQ também não descarta a descoberta de novas substâncias químicas tóxicas e a sua utilização nos campos de batalha por Estados não-Parte ou pelos Estados Parte em violação do CPAQ, ou por actores não estatais. Por esta razão, a interacção da OPAQ com uma comunidade científica global dinâmica, a observação cuidadosa da evolução da ciência e da tecnologia, o desenvolvimento de novas ou mais extensas medidas internacionais de verificação, e respectiva legislação, permitirão desenvolver procedimentos de prevenção, e de resposta adequada em tempo real, aos casos de emergência. No entanto, conter, prevenir, proteger e resgatar dos efeitos adversos de incidentes com produtos químicos tóxicos revelar-se-á sempre um desafio que requer coordenação e cooperação de todos os intervenientes, desde a comunidade científica até aos agentes de primeira resposta passando pelos industriais e legisladores.

A OPAQ encontra-se ciente desta necessidade e tem mudado consideravelmente nos últimos quatro anos, passando de uma organização voltada para si própria para uma orga- nização que quer ganhar visibilidade não só pela destruição dos arsenais químicos mas também pelo apoio à ciência e ao desenvolvimento.

Por último, a OPAQ não pode viver sem um exército de químicos e a comunidade dos químicos não pode existir sem considerar e reconhecer a OPAQ como um parceiro para o desenvolvimento do uso pacífico da Química.

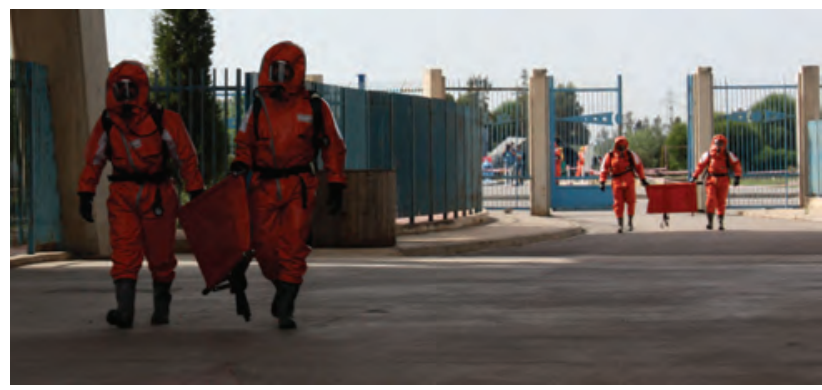

\section{AgRAdECIMENTOS}

Aos colegas da OPAQ porque sem o trabalho deles nunca teria recebido 1/500 da glória do Prémio Nobel.

Às minhas amigas João, Teresa, Maria do Céu, Célia, Lena,... pelo apoio e por não me deixarem sozinha na Holanda. À Doutora Maria João Marcelo Curto, pelo apoio e oportunidade de trabalhar nesta área.

À minha família, em especial à minha filha e ao meu marido pelo carinho e paciência, sem eles não me teria sido possível embarcar na aventura de ajudar a libertar o mundo destas armas terríveis.

\section{REFERÊNCIAS}

[1] Convenção para a Proibição de Armas Químicas, Diário da República, I Série-A, n. ${ }^{\circ}$ 169/96, 1. ${ }^{\circ}$ Suplemento

[2] Swedish Defense Research Agency: FOI briefing book Chemical Weapons -threat, effects and protection, Ed: L. Karlsson Engman, A. Lindblad, A-K. Tunemalm, O. Claesson, B. Lilliehöök, Number 2, 2002

[3] R. Pita, “Armas Químicas, La ciencia en manos del mal”, Plaza y Valdés Editores, 2008

[4] OPCW, The story of Chemical weapons ban, AO - 2875, 2007

[5] R. Pita, "Guerra Química Preguntas y Respuestas”, Ediciones Atlantis, Madrid, 2012

[6] J. Tucker, "War of Nerves: Chemical Warfare from World War I to Al-Qaeda”, New York, Pantheon Books, 2006

[7] http://disarmament.un.org/treaties/t/1925/text (UNODA, United Nations Office for Disarmament Affairs, acedido a 10-09-2014)

[8] Stockholm International Peace Research Institute (SIPRI): the problem of chemical and biological warfare, Volume1: the rise of CB Weapons, Estocolmo, AlmqvistWilsell, 1971

[9] http://www.medicalmuseum.mil/assets/images/galleries/ 
world_war_II/phosgene.jpg (NMHM, National Museum of Health and Medicine, acedido a 20 -09-2014)

[10] http://mercw.org/?option=com_content\&view=article\&id= 48\&Itemid=59 (MERCW, Modelling of Ecological Risks Related to Sea-Dumped Chemical Weapons, acedido a 1009-2014)

[11] http:www.cdc.gov/niosh (Centers for Disease Control and Precention, acedido a 20-09-2014)

[12] http://news.bbc.co.uk/onthisday/hi/dates/stories/march/16/ newsid_4304000/4304853.stm (BBC ON THIS DAY 16 March 1988: "Thousands die in Halabja gas attack”, BBC News, acedido a 10-09-2014)
[13] http://www.cbw-events.org.uk/syria.html (CBW Events, acedido a 10-09-2014)

[14] http://www.opcw.org/news/article/opcw-fact-finding-mission-compelling-confirmation-that-chlorinegas-used-as-weapon-in-syria/ (Organisation for the Prohibition of Chemical Weapons, acedido a 19-09-2014)

[15] B.V. Kgarebe, C.B. Rodrigues, "The Chemical Weapons Convention and the Work of the Organisation for the Prohibition Chemical Weapons (OPCW)" in Chemicals, Environment, Health: A Global Management Perspective, Philip Wexler, Jan van der Kolk, Asish Mohapatra \& Ravi Agarwal eds. CRC Press, 2011

\section{Actualidades Científicas}

\section{MOLÉCULAS DE BORO ANÁLOGAS AO FULERENO}

Desde a descoberta do fulereno $\mathrm{C}_{60}$ em 1985 e o subsequente prémio Nobel atribuído a Robert Curl, Harry Kroto e Richard Smalley, em 1996, os investigadores têm tentado obter estruturas semelhantes com outros elementos.

Em Junho de 2014, cálculos sistemáticos realizados por investigadores chineses sugerem a existência de um análogo de boro do fulereno, a molécula $\mathrm{B}_{38}$. Esta molécula, sugerida por Yanming Ma e seus colegas da Universidade de Jilin, Changchun, China, é um icosaedro constituído por 56 triângulos e quatro hexágonos. Trata-se do primeiro exemplo energeticamente estável de um cluster icosaédrico de boro a ser encontrado. O arranjo hexagonal dos átomos de boro e a sua densidade relativamente à disposição triangular resulta numa diferença energética HOMO-LUMO
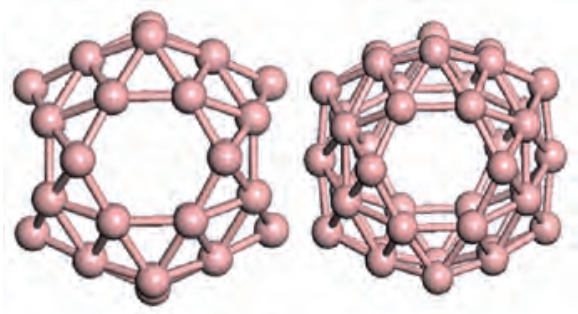
e aromaticidade elevadas, proporcionado uma estabilidade química inesperadamente alta.

Mais recentemente, em Julho de 2014, uma equipa de investigadores de universidades chinesas e americana reportaram a primeira evidência experimental da existência de uma estrutura de boro análoga ao fulereno, o anião $\mathrm{B}_{40}$. Este cluster foi obtido através da vaporização de boro e separação das estruturas formadas por espectrometria de massa. A análise por espectroscopia fotoelectrónica sugere que o anião se apresenta sob a forma de dois isómeros, um deles com uma estrutura análoga ao fulereno e outra quasi-planar. A existência destes dois isómeros foi prevista através de cálculos teóricos e o conjunto dos seus espectros calculados possui uma correspondência significativa com o espectro experimental. "Se essa interpretação estiver correcta, teremos observado o primeiro fulereno de boro”, referiu Lai-Sheng Wang, um dos membros da equipa.

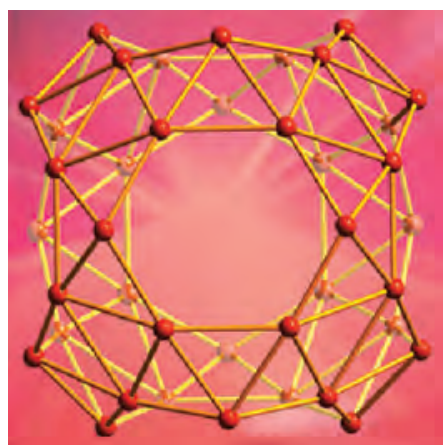

(Fontes: Buckyball boron, http://www.rsc.org/chemistryworld/2014/07/boron-cage-b38-fullerene; http://www.rsc.org/ chemistryworld/2014/07/first-experimental-evidence-boron-fullerene-bucky-ball-buckminsterfullerene; J. Lv et al, Nanoscale (2014) doi: 10.1039/c4nr01846j; H.-J. Zhai et al. Nature Chemistry (2014) doi:10.1038/nchem.1999
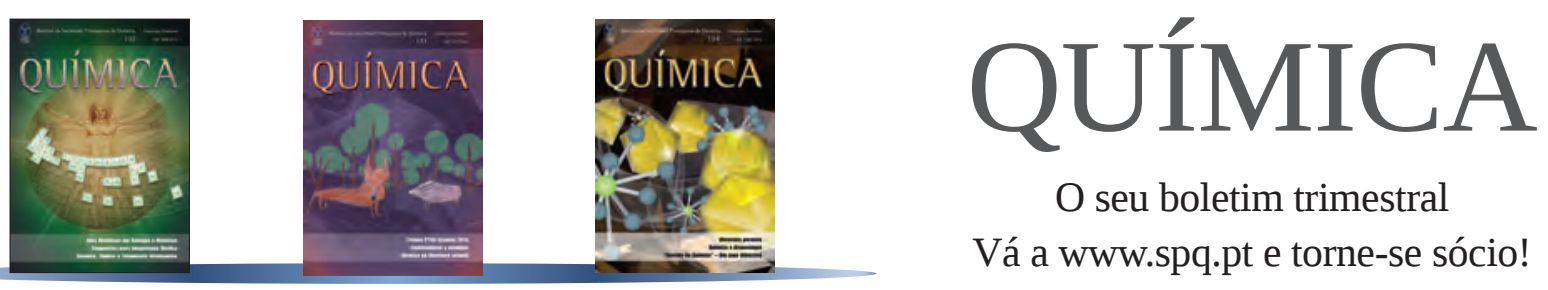

O seu boletim trimestral

Vá a www.spq.pt e torne-se sócio! 

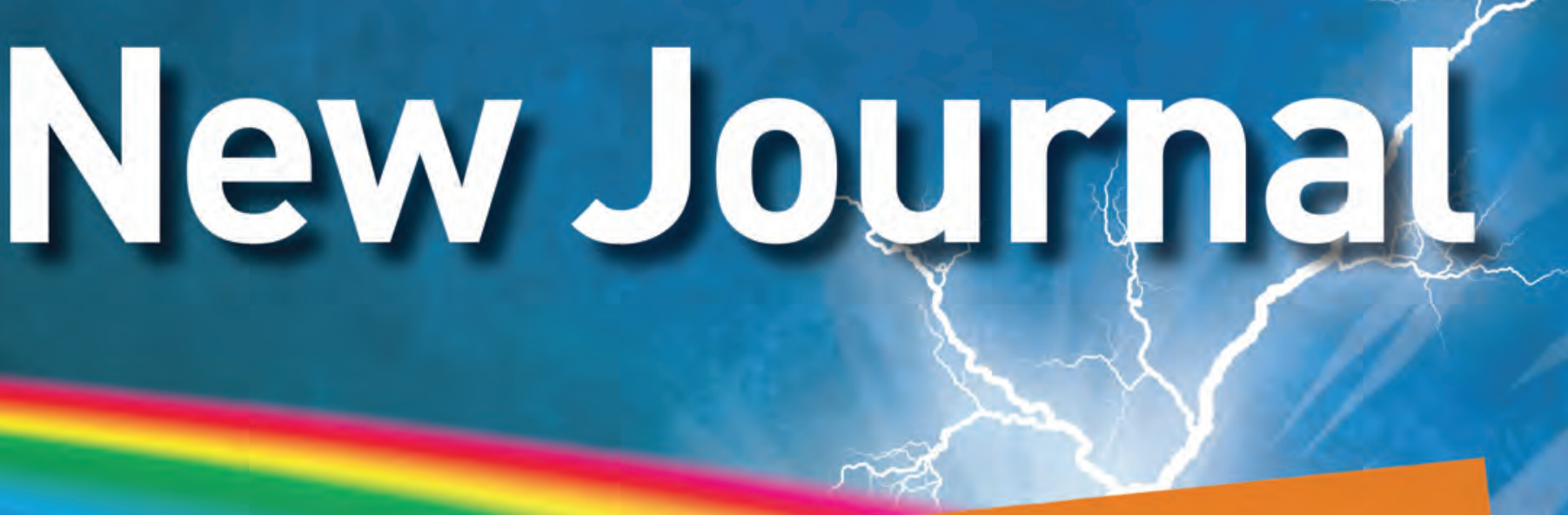

\section{ChemElectroChem}

is a sister journal of:
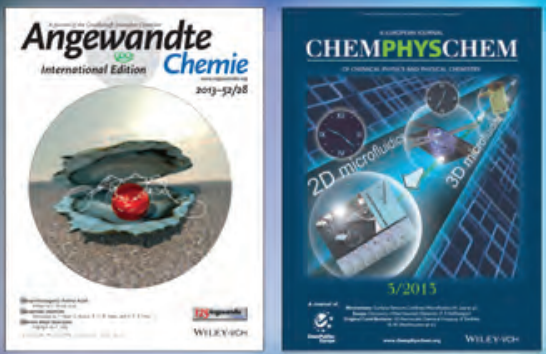

Co-Chairs of the Editorial Advisory Board:

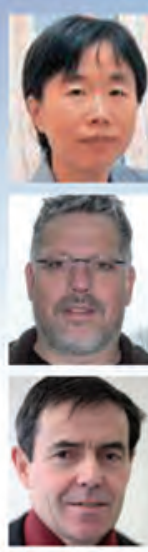

Bing-Wei Mao

(Xiamen University, China)

Wolfgang Schuhmann

(Ruhr-Universität Bochum, Germany)

Jean-Marie Tarascon

(Université de Picardie, France)

\section{CHEMELECTROCHEM}

CATALYSIS. BIO \& NANO. ENERGY \& MORE

All about

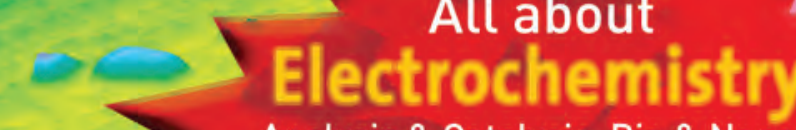

Analysis \& Catalysis, Bio \& Nano, Energy \& More

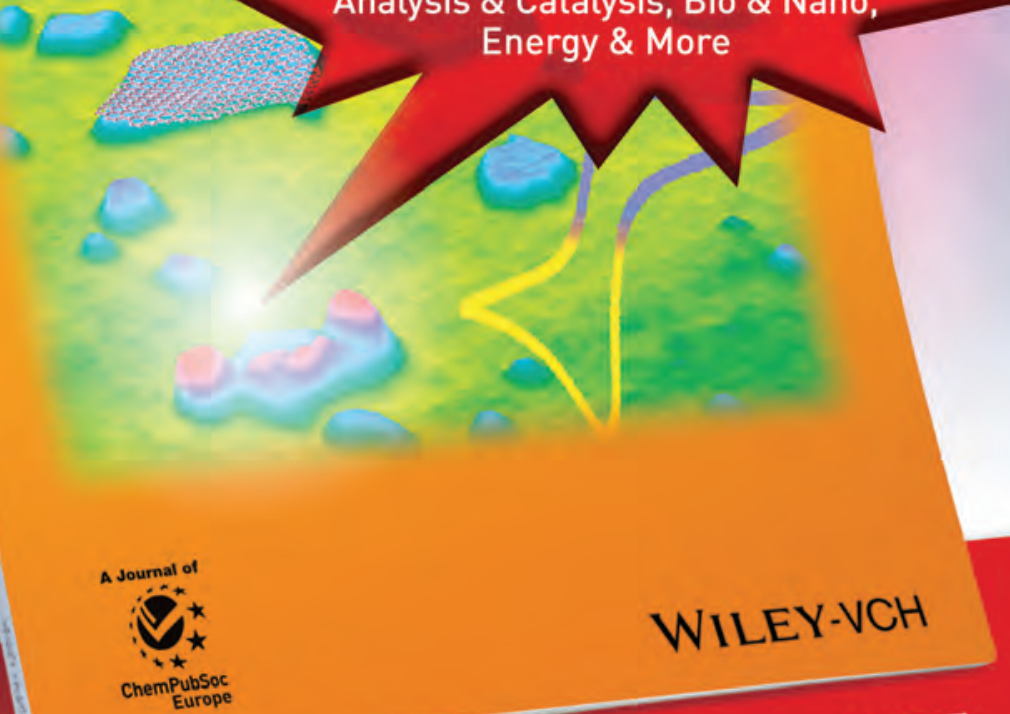

Free Online Access

In 2014 for all users from institutions that have registered

Ask your librarian to register for complimentary online access TODAY www.wileyonlinelibrary.com/newjournals-optin

\section{ChemElectroChem}

is a journal of ChemPubSoc Europe an organization comprising 16 European chemical societies.

www.chempubsoc.eu

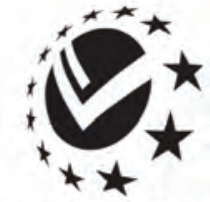

ChemPubSoc

Europe

\section{www.chemelectrochem.org}

WILEY-VCH 